\title{
Clinical implications of the newly defined concept of ventilator-associated events in trauma patients
}

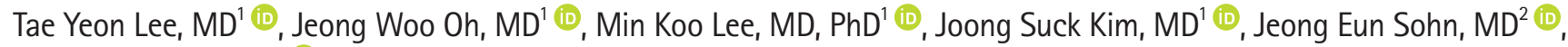 \\ Jeong Hwan Wi, MD² \\ ${ }^{1}$ Trauma Center, Cheju Halla General Hospital, Jeju, Korea \\ ${ }^{2}$ Department of Anesthesiology, Cheju Halla General Hospital, Jeju, Korea
}

Received: August 12, 2021

Revised: November 29, 2021

Accepted: December 7, 2021

Correspondence to

Tae Yeon Lee, MD

Trauma Center, Cheju Halla General

Hospital, 65 Doryeong-ro, Jeju 63127,

Korea

Tel: +82-64-740-5760

E-mail:arahant79@gmail.com
Purpose: Ventilator-associated pneumonia is the most common nosocomial infection in patients with mechanical ventilation. In 2013, the new concept of ventilator-associated events (VAEs) replaced the traditional concept of ventilator-associated pneumonia. We analyzed risk factors for VAE occurrence and in-hospital mortality in trauma patients who received mechanical ventilatory support.

Methods: In this retrospective review, the study population comprised patients admitted to the Jeju Regional Trauma Center from January 2020 to January 2021. Data on demographics, injury characteristics, and clinical findings were collected from medical records. The subjects were categorized into VAE and no-VAE groups according to the Centers for Disease Control and Prevention/National Healthcare Safety Network VAE criteria. We identified risk factors for VAE occurrence and in-hospital mortality.

Results: Among 491 trauma patients admitted to the trauma center, 73 patients who received ventilator care were analyzed. Patients with a chest Abbreviated Injury Scale (AIS) score $\geq 3$ had a 4.7-fold higher VAE rate (odds ratio [OR], 4.73; 95\% confidence interval [CI], 1.46-17.9), and those with a glomerular filtration rate (GFR) $<75 \mathrm{~mL} / \mathrm{min} / 1.73 \mathrm{~m}^{2}$ had 4.1 -fold higher odds of VAE occurrence (OR, 4.15; 95\% CI, 1.32-14.1) and a nearly 4.2-fold higher risk for in-hospital mortality (OR, 4.19; 95\% CI, 1.30-14.3). The median VAE-free duration of patients with chest AIS $\geq 3$ was significantly shorter than that of patients with chest AIS $<3(\mathrm{P}=0.013)$.

Conclusions: Trauma patients with chest AIS $\geq 3$ or GFR $<75 \mathrm{~mL} / \mathrm{min} / 1.73 \mathrm{~m}^{2}$ on admission should be intensively monitored to detect at-risk patients for VAEs and modify the care plan accordingly. VAEs should be closely monitored to identify infections early and to achieve desirable results. We should also actively consider modalities to shorten mechanical ventilation in patients with chest AIS $\geq 3$ to reduce VAE occurrence.

Keywords: Trauma centers; Pneumonia; Hospital mortality; Ventilator-associated pneumonia 


\section{INTRODUCTION}

Ventilator-associated pneumonia (VAP) is the most common nosocomial infection in patients requiring endotracheal tubes with mechanical ventilation [1]. The reported prevalence of VAP in trauma patients is about 4-fold higher than that in non-trauma patients [2]. Before 2013, the Centers for Disease Control and Prevention (CDC), the American Thoracic Society, and the Infectious Diseases Society of America collaborated to provide the surveillance definition of VAP [3-6]. However, over time, many concerns were raised about the effectiveness, reproducibility, and interpretation of VAP rates [7]. In 2013, the National Healthcare Safety Network (NHSN) replaced the previous definition of pneumonia with a classification of ventilator-associated events (VAEs). The concept of VAEs was defined to overcome many of the limitations of traditional VAP definitions, with the aim of establishing definitions that are objective, reproducible, automated, and a powerful predictor of poor outcomes [8]. VAEs are common complications in patients undergoing mechanical ventilation in the intensive care unit (ICU) $[9,10]$. These can lead to further complications that can extend the duration of mechanical ventilation, the length of stay (LOS) in the ICU, as well as costs, morbidity, and mortality $[11,12]$. Therefore, we analyzed the patients who received mechanical ventilator support at Jeju Regional Trauma Center.

\section{METHODS}

\section{Ethical statements}

The study was approved by the Institutional Review Board of the Cheju Halla General Hospital (No. 2021-L06-01). Informed consent was waived due to the retrospective nature of the study.

\section{Design and sample}

In this retrospective review, the study population comprised patients admitted to Jeju Regional Trauma Center between January 2020 and January 2021. For each patient, information regarding demographics (e.g., age and sex), injury characteristics, and clinical data were collected. Injury characteristics included injury mechanism (e.g., traffic accident, fall from height, slip down), Glasgow Coma Scale (GCS) score, Abbreviated Injury Scale (AIS), and Injury Severity Score (ISS). The GCS was calculated at the time of first contact with medical services before intubation and sedation. Clinical data were obtained from patients' electronic medical records. The data included hospital LOS in days, ICU LOS in days, and ventilator support days and other clinical and laboratory values such as positive end-expiratory pressure (PEEP), fraction of inspired oxygen $\left(\mathrm{FiO}_{2}\right)$, white blood cell count, hematocrit, hemoglobin, platelet count, serum creatinine, blood urea nitrogen, glomerular filtration rate (GFR), temperature, antimicrobial agents administered, and culture results.

\section{Ventilator-associated events}

VAEs, as defined by the NHSN [4], were categorized as ventilator-associated conditions (VACs), infection-related ventilator-associated complications (IVACs), and possible VAP (PVAP). Patients classified as having VACs had a baseline period of 2 days of stable or improved $\mathrm{FiO}_{2}$ or PEEP followed by deterioration of oxygenation. Those categorized as having IVACs met the criteria for VACs, had a core temperature $>38^{\circ} \mathrm{C}$ or $<36^{\circ} \mathrm{C}$ or had a white blood cell $>12,000$ or $<4,000$ cells $/ \mathrm{mm}^{3}$, and were administered eligible antimicrobial agents that were continued for more than 4 days. For PVAP, in addition to meeting the criteria for IVAC, patients had $>10^{5}$ colony-forming units in their tracheal aspirates and $>10^{4}$ colony-forming units of microorganisms in cultures of bronchoalveolar lavage specimens (Table 1) [13].

\section{Statistics}

Demographics, injury characteristics, clinical data, comorbidities, and nosocomial complications were compared between the two groups. The independent $t$-test and Fisher exact test were used for continuous and categorical variables, respectively. A logistic regression model adjusted for age, sex, GCS score, GFR, chest and head AIS, and ISS was used to estimate odds ratios (ORs) and associated 95\% confidence intervals (CIs) for VAE occurrence and in-hospital mortality. A Cox proportional hazard model was used for investigating the association between VAE occurrence and several variables over time. The Kaplan-Meier method and the log-rank test were used for estimating the VAEfree rate curve and for statistical comparisons between the two groups. All tests of significance were two-tailed, and a P-value of $<0.05$ was considered statistically significant. Statistical analyses were performed using $\mathrm{R}$ statistics ver. 4.0.2. (The R Foundation for Statistical Computing, Vienna, Austria; https://www.r-project. $\operatorname{org} /)$.

\section{RESULTS}

From January 2020 to January 2021, 492 patients were admitted to Jeju Regional Trauma Center, of whom 210 patients received ventilator support. Among them, 84 patients had at least 4 calendar days of ventilator support. In accordant with 2013 CDC/ 
Table 1. NHSN VAE criteria

\begin{tabular}{|c|c|c|}
\hline \multicolumn{3}{|c|}{ NHSN surveillance guidelines for diagnosis of VAE } \\
\hline Name: description & Dependent qualification & Definition \\
\hline \multirow[t]{3}{*}{ VAC: new respiratory deterioration } & \multirow{3}{*}{$\begin{array}{l}\geq 2 \text { calendar days of stable or decreasing daily } \\
\text { minimum PEEP or daily minimum } \mathrm{FIO}_{2}\end{array}$} & Followed by a daily \\
\hline & & OR \\
\hline & & $\begin{array}{l}\text { Minimum } \mathrm{FIO}_{2} \text { by }>20 \text { points sustained for } \geq 2 \\
\text { calendar days }\end{array}$ \\
\hline & Excludes the first 2 days of mechanical ventilation & OR \\
\hline & & Leukocyte count: $\leq 4,000$ or $\geq 12,000$ cells $/ \mathrm{mm}^{3}$ \\
\hline & & AND \\
\hline & & One or more new antibiotics continued for $\geq 4$ days \\
\hline $\begin{array}{l}\text { Possible VAP: IVAC+qualitative } \\
\text { evidence of pulmonary infection }\end{array}$ & $\begin{array}{l}\text { Within } 2 \text { calendar days before or after onset of a } \\
\text { VAC }\end{array}$ & $\begin{array}{l}\text { Gram staining of endotracheal aspirate or BAL } \\
\text { showing } \geq 25 \text { neutrophils and } \leq 10 \text { epithelial cells } \\
\text { per low-power field }\end{array}$ \\
\hline \multirow[t]{4}{*}{$\begin{array}{l}\text { Probable VAP: IVAC+qualitative } \\
\text { evidence of pulmonary infection }\end{array}$} & $\begin{array}{l}\text { Within } 2 \text { calendar days before or after onset of a } \\
\text { VAC }\end{array}$ & $\begin{array}{l}\text { Positive culture of endotracheal aspirate } \geq 10^{5} \mathrm{CFU} / \\
\mathrm{mL} \text {, positive BAL culture with } \geq 10^{4} \mathrm{CFU} / \mathrm{mL} \text {, or } \\
\text { positive culture of protected specimen brush } \geq 10^{3} \\
\text { CFU/mL }\end{array}$ \\
\hline & Excludes the first 2 days of mechanical ventilation & OR \\
\hline & & $\begin{array}{l}\text { One of the following (without requirement for } \\
\text { purulent secretions): }\end{array}$ \\
\hline & & $\begin{array}{l}\text { Positive pleural fluid culture (where specimen } \\
\text { was obtained during thoracentesis or initial } \\
\text { placement of chest tube and NOT from } \\
\text { indewelling chest tube) }\end{array}$ \\
\hline
\end{tabular}

Highlights the stepwise respiratory deterioration associated with VAC, IVAC, possible pneumonia, and probable pneumonia with specific, objective criteria that define each category. Sputum cultures excludes the following: normal respiratory/oral flora, mixed respiratory/oral flora or equivalent; Candida species or yeast not otherwise specified; coagulase-negative Staphylococcus species; and Enterococcus species.

NHSN, National Healthcare Safety Network; VAE, ventilator-associated event; VAC, ventilator-associated condition; IVAC, infection-related ventilator-associated complication; PEEP, positive end-expiratory pressure; $\mathrm{FIO}_{2}$, fraction of inspired oxygen; VAP, ventilator-associated pneumonia; BAL, bronchoalveolar lavage; CFU, colony-forming unit.

Adapted from Spalding et al. [13] with permission from Elsevier.

NHSN VAE surveillance criteria, those who were under 18 years old $(n=4)$, received extracorporeal membrane oxygenation therapy $(n=6)$, and had incomplete data $(n=1)$ were excluded from this study $(\mathrm{n}=11)$. Finally, the study population comprised 73 patients, of whom 48 had no VAEs (65.8\%), 16 met the definition for VACs (21.9\%), three met the criteria for IVACs (4.1\%), and six met the criteria for PVAP (8.2\%). The subjects categorized as belonging to the no-VAE group had no VAEs during mechanical ventilatory support. The subjects in the VAE group had at least one VAE criterion (including VACs, IVACs, and PVAP). There were no significant differences in demographics, comorbidities, injury characteristics, clinical data, and laboratory values between the two groups (Table 2). Additionally, there were no significant differences in ICU LOS $(\mathrm{P}=0.200)$, ventilator support days $(\mathrm{P}=0.164)$, the incidence of nosocomial complications, and in-hospital mortality $(\mathrm{P}=0.111)$ between the two groups (Tables $3,4)$. However, the VAE subjects were more likely to have higher GCS scores $(\mathrm{P}=0.012)$ and chest AIS $(\mathrm{P}=0.024)$ (Tables 2, 5) and less likely to have normal kidney function as measured by the GFR $(P=0.001)$ (Table 3$)$ than the no-VAE subjects. The VAE 
Table 2. Comparison of demographics, comorbidities, and injury characteristics by VAE status

\begin{tabular}{|c|c|c|c|}
\hline Variable & $\begin{array}{c}\text { No VAE } \\
(\mathrm{n}=48)\end{array}$ & $\begin{array}{c}\text { VAE } \\
(\mathrm{n}=25)\end{array}$ & P-value \\
\hline Age (yr) & $57.6 \pm 19.1$ & $64.4 \pm 16.5$ & 0.138 \\
\hline \multicolumn{4}{|l|}{ Sex } \\
\hline Male & 62.5 & 80.0 & 0.207 \\
\hline Female & 37.5 & 20.0 & \\
\hline \multicolumn{4}{|l|}{ Comorbidity } \\
\hline Hypertension & 37.5 & 40.0 & $>0.999$ \\
\hline Diabetes mellitus & 8.3 & 20.0 & 0.287 \\
\hline Chronic kidney disease & 0 & 8.0 & 0.218 \\
\hline Cerebrovascular attack & 10.4 & 12.0 & $>0.999$ \\
\hline Tumor & 0 & 8.0 & 0.218 \\
\hline Liver disease & 6.2 & 0 & 0.512 \\
\hline \multicolumn{4}{|l|}{ Mechanism of injury } \\
\hline Traffic accident & 43.8 & 56.0 & 0.455 \\
\hline Fall from height & 20.8 & 12.0 & 0.539 \\
\hline Slip down & 14.6 & 16.0 & $>0.999$ \\
\hline Struck by object & 6.2 & 12.0 & 0.689 \\
\hline Glasgow Coma Scale score & $9.2 \pm 4.1$ & $11.8 \pm 4.1$ & $0.012^{*}$ \\
\hline Injury Severity Score & $25.8 \pm 10.2$ & $23.2 \pm 11.2$ & 0.813 \\
\hline \multicolumn{4}{|l|}{ Abbreviated Injury Scale } \\
\hline Head & $3.35 \pm 1.92$ & $2.86 \pm 2.00$ & 0.327 \\
\hline Face & $0.41 \pm 0.90$ & $0.45 \pm 1.01$ & 0.858 \\
\hline Chest & $1.43 \pm 1.60$ & $2.36 \pm 1.53$ & $0.024^{*}$ \\
\hline Abdomen & $0.92 \pm 1.34$ & $0.68 \pm 1.17$ & 0.469 \\
\hline Extremity & $0.86 \pm 1.34$ & $1.27 \pm 1.12$ & 0.214 \\
\hline External & $0.67 \pm 0.89$ & $0.59 \pm 0.59$ & 0.715 \\
\hline
\end{tabular}

Values are presented as mean \pm standard deviation or percentage. P-value obtained using chi-square test and Student t-tests for categorical and continuous variables, respectively.

VAE, ventilator-associated event.

${ }^{*} \mathrm{P}<0.05$.

subjects had a higher number of bronchoscopies $(\mathrm{P}=0.004)$ and were more likely to have acute respiratory distress syndrome $(\mathrm{P}=0.021)$ than the no-VAE subjects (Table 4). Continuous values were converted to categorical values for logistic regression analysis. The cutoff values were set as 65 years for age, 3 points for AIS, 15 points for ISS, 7 points for GCS, and $75 \mathrm{~mL} / \mathrm{min} / 1.73$ $\mathrm{m}^{2}$ for GFR. In the multivariate analysis, the risk for VAE occurrence was 4.7 -fold higher in patients with chest AIS $\geq 3$ (OR, 4.73; 95\% CI, 1.46-17.9) and 4.1-fold higher in those with a GFR $<75 \mathrm{~mL} / \mathrm{min} / 1.73 \mathrm{~m}^{2}$ (OR, 4.15; 95\% CI, 1.32-14.1). The in-hospital mortality risk was more than 4 -fold higher in patients with a GFR $<75 \mathrm{~mL} / \mathrm{min} / 1.73 \mathrm{~m}^{2}$ (OR, 4.19; 95\% CI, 1.30-14.3) (Table 6). In addition, VAEs occurred in $50.0 \%$ of patients with a chest AIS $\geq 3$ within 15 days of mechanical ventilatory support (Fig.
Table 3. Comparison of clinical characteristics and laboratory values by VAE status

\begin{tabular}{|c|c|c|c|}
\hline Variable & No VAE $(n=48)$ & $\operatorname{VAE}(\mathrm{n}=25)$ & P-value \\
\hline \multicolumn{4}{|l|}{ Clinical values } \\
\hline $\mathrm{SBP}(\mathrm{mmHg})$ & $130 \pm 51$ & $134 \pm 47$ & 0.760 \\
\hline $\mathrm{DBP}(\mathrm{mmHg})$ & $77 \pm 29$ & $79 \pm 27$ & 0.843 \\
\hline Pulse rate (/min) & $86 \pm 29$ & $89 \pm 31$ & 0.631 \\
\hline Respiratory rate (/min) & $22 \pm 7$ & $22 \pm 4$ & 0.947 \\
\hline Body temperature $\left({ }^{\circ} \mathrm{C}\right)$ & $36.3 \pm 0.8$ & $36.4 \pm 0.5$ & 0.291 \\
\hline \multicolumn{4}{|l|}{ Blood cell count } \\
\hline WBC $\left(\times 1,000\right.$ cells $\left./ \mathrm{mm}^{3}\right)$ & $13.4 \pm 5.4$ & $12.2 \pm 6.2$ & 0.421 \\
\hline Hemoglobin (g/dL) & $12.5 \pm 2.3$ & $12.6 \pm 1.9$ & 0.845 \\
\hline Hematocrit (\%) & $36.3 \pm 6.7$ & $37.1 \pm 5.3$ & 0.606 \\
\hline Platelet $(\times 1,000 / \mu \mathrm{L})$ & $228 \pm 91$ & $214 \pm 73$ & 0.512 \\
\hline \multicolumn{4}{|l|}{ Chemistry } \\
\hline BUN (mg/dL) & $19 \pm 15$ & $22 \pm 15$ & 0.422 \\
\hline Creatinine (mg/dL) & $0.9 \pm 0.5$ & $1.7 \pm 2.4$ & 0.125 \\
\hline $\operatorname{GFR}\left(\mathrm{mL} / \mathrm{min} / 1.73 \mathrm{~m}^{2}\right)$ & $98.5 \pm 46.5$ & $68.4 \pm 27.8$ & $0.001^{* *}$ \\
\hline $\mathrm{CRP}(\mathrm{mg} / \mathrm{dL})$ & $1.9 \pm 7.3$ & $0.6 \pm 2.1$ & 0.264 \\
\hline $\mathrm{CPK}(\mathrm{U} / \mathrm{L})$ & $366 \pm 331$ & $441 \pm 482$ & 0.508 \\
\hline \multicolumn{4}{|l|}{ ABGA } \\
\hline $\mathrm{pH}$ & $7.3 \pm 0.1$ & $7.4 \pm 0.1$ & 0.512 \\
\hline $\mathrm{PaCO}_{2}(\mathrm{mmHg})$ & $35.8 \pm 8.1$ & $33.9 \pm 6.5$ & 0.334 \\
\hline $\mathrm{PaO}_{2}(\mathrm{mmHg})$ & $165.7 \pm 69.9$ & $137.6 \pm 58.1$ & 0.094 \\
\hline Saturation (\%) & $97.6 \pm 4.3$ & $97.4 \pm 3.3$ & 0.836 \\
\hline Lactate (mg/dL) & $35.5 \pm 22.0$ & $49.5 \pm 33.7$ & 0.508 \\
\hline
\end{tabular}

Values are presented as mean \pm standard deviation. P-value obtained using Student t-tests for continuous variables.

VAE, ventilator-associated event; SBP, systolic blood pressure; DBP, diastolic blood pressure; WBC, white blood cell; BUN, blood urea nitrogen; GFR, glomerular filtration rate; CRP, C-reactive protein; CPK, creatine phosphokinase; $\mathrm{ABGA}$, arterial blood gas analysis.

${ }^{*} \mathrm{P}<0.01$

1). The median VAE-free duration of patients with a chest AIS $\geq 3$ was significantly shorter than that of patients with a chest AIS $<3(\mathrm{P}=0.013)$.

\section{DISCUSSION}

To our best knowledge, this study is the first surveillance study of the incidence, risk factors, and outcomes with the newly defined concept of VAEs in trauma patients. The present study revealed that several factors were associated with VAE occurrence and in-hospital mortality in polytrauma patients.

The VAE group was more likely to have higher GCS scores, which were used to define the severity of traumatic brain injuries (TBIs) in several studies. Patients with TBIs often suffer from profound suppression of cellular immunity and impaired con- 
sciousness [14], and they usually require endotracheal intubation and mechanical ventilatory care, both of which increased the incidence of VAP. Therefore, severe TBI patients were more vulnerable to VAP [15]. However, chest injury and the combination of chest injury and TBI were found to be independent predictors for

Table 4. Comparison of clinical outcomes by VAE status

\begin{tabular}{lccc}
\hline Variable & No VAE $(\mathrm{n}=48)$ & VAE $(\mathrm{n}=25)$ & P-value \\
\hline MV day & $17.7 \pm 15.4$ & $25.2 \pm 23.9$ & 0.164 \\
Length of stay & & & \\
$\quad$ ICU in day & $26.3 \pm 22.0$ & $33.7 \pm 25.7$ & 0.200 \\
Hospital in day & $86.8 \pm 69.9$ & $61.0 \pm 33.9$ & $0.037^{\star}$ \\
Bronchoscopy & $3.9 \pm 4.7$ & $14.1 \pm 15.9$ & $0.004^{* *}$ \\
Complication & & & \\
AKI & $4(8.3)$ & $3(12.0)$ & 0.931 \\
ARDS & 0 & $4(16.0)$ & $0.021^{\star}$ \\
CPR & $4(8.3)$ & $4(16.0)$ & 0.548 \\
VTE & $7(14.6)$ & $4(16.0)$ & 1.000 \\
PTE & $8(16.7)$ & $5(20.0)$ & 0.975 \\
UTI & $3(6.2)$ & $1(4.0)$ & 1.000 \\
CRBSI & $1(2.1)$ & $1(4.0)$ & 1.000 \\
Unplanned intubation & $6(12.5)$ & $7(28.0)$ & 0.187 \\
Unplanned operation & $6(12.5)$ & $4(16.0)$ & 0.957 \\
Unplanned ICU transfer & $5(10.4)$ & $6(24.0)$ & 0.232 \\
In-hospital mortality & $11(22.9)$ & $11(44.0)$ & 0.111 \\
\hline
\end{tabular}

Values are presented as mean \pm standard deviation or number (\%). P-value obtained using chi square test and student t-tests for categorical and continuous variables, respectively.

VAE, ventilator-associated event; $\mathrm{MV}$, mechanical ventilator; ICU, intensive care unit; AKI, acute kidney injury; ARDS, acute respiratory distress syndrome; CPR, cardiopulmonary resuscitation; VTE, venous thromboembolism; PTE, pulmonary thromboembolism; UTI, urinary tract infection; CRBSI, catheter-related blood stream infection.

${ }^{\star} \mathrm{P}<0.05 ;{ }^{\star \star} \mathrm{P}<0.01$ the development of pneumonia in polytrauma patients [15]. This suggests that TBI itself was not associated with the development of pneumonia. Our results showed that patients in the VAE group had relatively higher GCS scores, although the GCS scores were not related to in-hospital mortality.

Second, blunt chest trauma may cause intra-thoracic organ injuries, which may lead to serious complication and mortality in polytrauma patients [16]. The risk of respiratory failure and subsequent pneumonia development depends on the severity of the chest injury [17]. Hofman et al. [18] reported that although chest trauma was not an independent risk factor for mortality, it was an independent risk factor for pneumonia. Their results showed that a chest AIS $\geq 3$ in poly-traumatized patients was associated with an increased risk of pneumonia $(\mathrm{OR}, 4.193 ; \mathrm{P}=0.004)$ in multivariate regression analysis. The present study showed similar results, in that the patient with a chest AIS $\geq 3$ were likely to have a higher risk of VAE.

Table 5. Chest Abbreviated Injury Scale (AIS)

\begin{tabular}{|c|c|c|}
\hline AIS 2008 & Skeletal & Lung \\
\hline \multirow[t]{2}{*}{1} & Contusion & - \\
\hline & 1 Rib fracture & - \\
\hline \multirow[t]{2}{*}{2} & 2 Rib fractures & $\begin{array}{l}\text { Unilateral contusion with minor }<1 \\
\text { lobe }\end{array}$ \\
\hline & Sternal fracture & Pneumothorax, pneumomedisatinum \\
\hline \multirow[t]{2}{*}{3} & $\geq 3$ Ribs & $\begin{array}{l}\text { Unilateral contusion with major } \geq 1 \\
\text { lobe }\end{array}$ \\
\hline & 3-5 Flail chest & Hemopneumothorax \\
\hline \multirow[t]{3}{*}{4} & $\geq 5$ Flail chest & Bilateral contusion with major $\geq 1$ lobe \\
\hline & & Pneumothorax $>50 \%$ collapse \\
\hline & & $\begin{array}{l}\text { Hemothorax }>1,000 \mathrm{~mL} \text { in unilateral } \\
\text { cavity }\end{array}$ \\
\hline 5 & Bilateral flail chest & Tension pneumothorax \\
\hline
\end{tabular}

Table 6. Multivariate analysis of factors associated with VAE occurrence and in-hospital mortalit

\begin{tabular}{|c|c|c|c|c|}
\hline \multirow{2}{*}{ Variable } & \multicolumn{2}{|c|}{ VAE occurrence } & \multicolumn{2}{|c|}{ In-hospital mortality } \\
\hline & OR $(95 \% \mathrm{CI})$ & P-value & OR $(95 \%$ CI $)$ & P-value \\
\hline Male sex & $2.25(0.66-8.81)$ & 0.2102 & $0.54(0.15-1.90)$ & 0.3357 \\
\hline Age $\geq 65$ years & $0.95(0.25-3.32)$ & 0.9365 & $2.14(0.67-7.33)$ & 0.2167 \\
\hline Injury Severity Score $\geq 15$ & $0.30(0.05-1.73)$ & 0.1841 & $1.96(0.34-12.4)$ & 0.4554 \\
\hline \multicolumn{5}{|l|}{ Abbreviated Injury Scale } \\
\hline Chest $\geq 3$ & $4.73(1.46-17.9)$ & $0.0135^{\star}$ & $0.48(0.12-1.70)$ & 0.2662 \\
\hline Head $\geq 3$ & $1.24(0.31-5.61)$ & 0.7615 & $0.49(0.12-2.04)$ & 0.3151 \\
\hline GFR $<75 \mathrm{~mL} / \mathrm{min} / 1.73 \mathrm{~m}^{2}$ & $4.15(1.32-14.1)$ & $0.0170^{*}$ & $4.19(1.30-14.3)$ & $0.0181^{*}$ \\
\hline $\operatorname{VAE}(+)$ & & & $2.53(0.67-10.1)$ & 0.1733 \\
\hline
\end{tabular}

P-value obtained from logistic regression model.

VAE, ventilator-associated event; OR, odds ratio; CI, confidence interval; GFR, glomerular filtration rate. ${ }^{\star} \mathrm{P}<0.05$. 


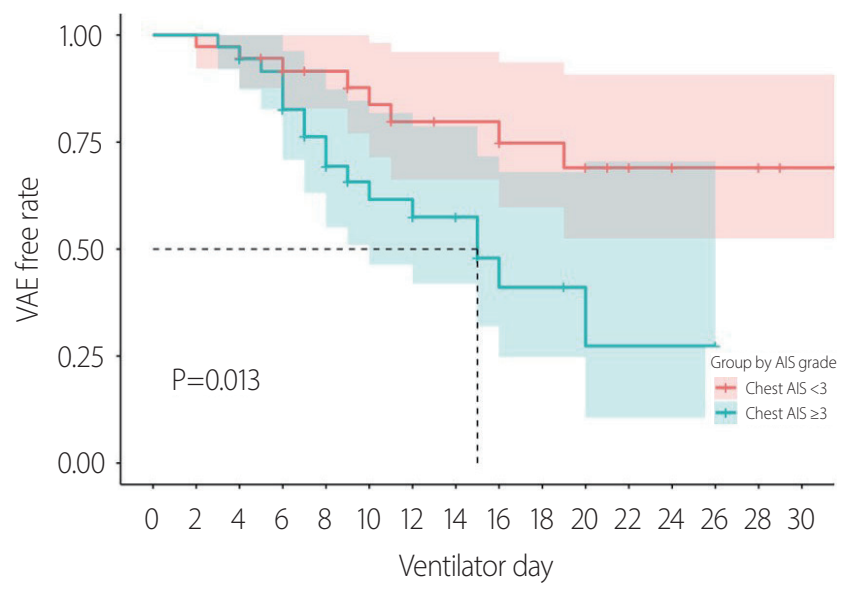

Fig. 1. Ventilator-associated event (VAE) free rate curves between low-grade and high-grade chest Abbreviated Injury Scale (AIS) group (estimated by the Kaplan-Meier log-rank test).

Table 7. Risk factor associated with posttraumatic acute kidney injury

\begin{tabular}{lccc}
\hline & $\begin{array}{c}\text { GFR }<75 \mathrm{~mL} / \\
\mathrm{min} / 1.73 \mathrm{~m}^{2}\end{array}$ & $\begin{array}{c}\mathrm{GFR} \geq 75 \mathrm{~mL} / \\
\mathrm{min} / 1.73 \mathrm{~m}^{2}\end{array}$ & P-value \\
\hline Categorical values & & & \\
$\quad$ Male sex & $20(27.4)$ & $30(41.1)$ & 0.5993 \\
Hypertension & $15(20.5)$ & $13(17.8)$ & $0.0388^{*}$ \\
$\quad$ Diabetes mellitus & $5(6.8)$ & $4(5.4)$ & 0.2765 \\
Continuous values & & & \\
Age (yr) & $66.5 \pm 16.3$ & $56.0 \pm 18.7$ & $0.0153^{*}$ \\
ISS & $22.6 \pm 10.7$ & $26.2 \pm 10.3$ & 0.1648 \\
ICU stay (day) & $35.1 \pm 29.0$ & $25.2 \pm 18.9$ & 0.1179 \\
MVD & $26.7 \pm 25.4$ & $16.5 \pm 12.8$ & $0.0595^{\dagger}$ \\
\hline
\end{tabular}

Values are presented as number (\%) or mean \pm standard deviation. P-value obtained from t-test.

GFR, glomerular filtration rate; ISS, Injury Severity Score; ICU, intensive care unit; MVD, mechanical ventilator days.

${ }^{\star} \mathrm{P}<0.05 ;{ }^{\dagger} \mathrm{P}<0.1$.

Lastly, several recent studies showed that reduced renal function was associated with an increased risk of pneumonia [19]. An explanation for this is that decreased renal function may increase the risk of infection due to immune impairment, which is supported by reports of abnormalities in neutrophil and lymphocyte function [20]. The observed association between kidney function and infection may be due to an increased susceptibility to infection and/or a greater severity of infection in older patients with chronic kidney disease [21]. Our study also showed similar results, as decreased renal function was associated with VAE occurrence and in-hospital mortality. VAEs themselves did not affect the risk of in-hospital mortality. However, patients with a low GFR showed a statistically significant increase in mortality. In other words, posttraumatic acute kidney injury (AKI) can be a direct risk factor for mortality in trauma patients. Harrois et al. [22] performed a systematic review and meta-analysis of AKIs in trauma patients that included 24 studies with 25,182 patients. In their analysis, they observed that posttraumatic AKI was associated with a 3.4-fold increased risk of mortality (95\% CI, 2.1-5.7) and they observed that the risk factors for posttraumatic AKI were specific race, old age, hypertension, and diabetes mellitus. In our study, we performed a subgroup analysis based on GFR that showed statistically significant differences in patients' age $(\mathrm{P}=0.0153)$ and hypertension $(\mathrm{P}=0.0388)$ between the two groups (Table 7).

This study had several limitations. First, the study period was short, and the sample size was small. Although we were able to derive several risk factors associated with VAE occurrence and in-hospital mortality, it is necessary to estimate more significant risk factors using a largescale study in the future. Second, although the number of bronchoscopies was significantly higher $(\mathrm{P}=0.004)$ in the VAE group, we were not able to establish a significant effect of bronchoscopy on VAE occurrence and in-hospital mortality. However, there is some evidence that diagnostic bronchoscopy may improve VAP-related outcomes $[23,24]$. Bronchoscopic sputum aspiration has also shown promising results and significant benefits in various indicators, including shorter mechanical ventilation, reduced hospital LOS, and improved weaning success rates [25]. Considering these points, it will also be necessary to study whether bronchoscopy may affect the occurrence and mortality rate of VAE in trauma patients. Third, in this study, the effect of tracheostomy was not considered in patients with a mechanical ventilator. However, tracheostomy may have several advantages, such as improved airway suctioning, less direct laryngeal injury, decreased airway resistance for promoting weaning from mechanical ventilation, and decreased risk for nosocomial pneumonia [26]. Thus, research on the association between tracheostomy and VAE occurrence is needed in the future.

In conclusion, based on our study results, traumatized patients with chest AIS $\geq 3$ or GFR $<75 \mathrm{~mL} / \mathrm{min} / 1.73 \mathrm{~m}^{2}$ on admission should be intensively monitored to detect patients at risk for VAEs and modify their care plans to reduce the risk of VAEs during mechanical ventilator support. VAEs should be closely monitored to identify infections in the target subjects early and to achieve desirable results. We should also actively consider modalities that can minimize the duration of mechanical ventilators (less than 15 days) in patients with a chest AIS $\geq 3$ to reduce VAE occurrence. 


\section{NOTES}

\section{Ethical statements}

The study was approved by the Institutional Review Board of the Cheju Halla General Hospital (No. 2021-L06-01). Informed consent was waived due to the retrospective nature of the study.

\section{Conflicts of interest}

The authors have no conflicts of interest to declare.

\section{Funding}

None.

\section{Author contributions}

Conceptualization: TYL, JWO, MKL, JSK, JES; Data curation: TYL, JWO, JES, JHW; Formal analysis: MKL, JSK, JHW; Methodology: TYL, JWO, MKL, JES; Project administration: TYL, JWO; Visualization: JSK, JHW; Writing-original draft: all authors; Writing-review \& editing: all authors.

All authors read and approved the final manuscript.

\section{Additional information}

This study was posted at the 2021 Pan Pacific Trauma Congress (PPTC).

\section{REFERENCES}

1. O'Grady NP, Murray PR, Ames N. Preventing ventilator-associated pneumonia: does the evidence support the practice. JAMA 2012;307:2534-9.

2. Cook A, Norwood S, Berne J. Ventilator-associated pneumonia is more common and of less consequence in trauma patients compared with other critically ill patients. J Trauma 2010;69:1083-91.

3. Torres A, Ewig S, Lode H, Carlet J; European HAP working group. Defining, treating and preventing hospital acquired pneumonia: European perspective. Intensive Care Med 2009;35:9-29.

4. Magill SS, Klompas M, Balk R, et al. Developing a new, national approach to surveillance for ventilator-associated events. Am J Crit Care 2013;22:469-73.

5. Magill SS, Fridkin SK. Improving surveillance definitions for ventilator-associated pneumonia in an era of public reporting and performance measurement. Clin Infect Dis 2012;54:37880.

6. Horan TC, Andrus M, Dudeck MA. CDC/NHSN surveil- lance definition of health care-associated infection and criteria for specific types of infections in the acute care setting. Am J Infect Control 2008;36:309-32.

7. Klompas M, Platt R. Ventilator-associated pneumonia: the wrong quality measure for benchmarking. Ann Intern Med 2007;147:803-5.

8. Klompas M. Ventilator-associated events: what they are and what they are not. Respir Care 2019;64:953-61.

9. Diaz E, Rodriguez AH, Rello J. Ventilator-associated pneumonia: issues related to the artificial airway. Respir Care 2005;50:900-6.

10. Hunter JD. Ventilator associated pneumonia. BMJ 2012;344: e3325.

11. Esteban A, Anzueto A, Frutos F, et al. Characteristics and outcomes in adult patients receiving mechanical ventilation: a 28-day international study. JAMA 2002;287:345-55.

12. Rouze A, Martin-Loeches I, Nseir S. Airway devices in ventilator- associated pneumonia pathogenesis and prevention. Clin Chest Med 2018;39:775-83.

13. Spalding MC, Cripps MW, Minshall CT. Ventilator-associated pneumonia: new definitions. Crit Care Clin 2017;33:27792.

14. Griffin GD. The injured brain: TBI, mTBI, the immune system, and infection: connecting the dots. Mil Med 2011;176: 364-8.

15. Li Y, Liu C, Xiao W, Song T, Wang S. Incidence, risk factors, and outcomes of ventilator-associated pneumonia in traumatic brain injury: a meta-analysis. Neurocrit Care 2020;32: $272-85$.

16. Huber S, Biberthaler P, Delhey P, et al. Predictors of poor outcomes after significant chest trauma in multiply injured patients: a retrospective analysis from the German Trauma Registry (Trauma Register DGU ${ }^{\circledR}$ ). Scand J Trauma Resusc Emerg Med 2014;22:52.

17. Stewart RM, Corneille MG. Common complications following thoracic trauma: their prevention and treatment. Semin Thorac Cardiovasc Surg 2008;20:69-71.

18. Hofman M, Andruszkow H, Kobbe P, Poeze M, Hildebrand F. Incidence of post-traumatic pneumonia in poly-traumatized patients: identifying the role of traumatic brain injury and chest trauma. Eur J Trauma Emerg Surg 2020;46:11-9.

19. Vart P, Bettencourt-Silva JH, Metcalf AK, Bowles KM, Potter JF, Myint PK. Low estimated glomerular filtration rate and pneumonia in stroke patients: findings from a prospective stroke registry in the East of England. Clin Epidemiol 2018; 10:887-96. 
20. Girndt M, Sester U, Sester M, Kaul H, Kohler H. Impaired cellular immune function in patients with end-stage renal failure. Nephrol Dial Transplant 1999;14:2807-10.

21. Dalrymple LS, Katz R, Kestenbaum B, et al. The risk of infection-related hospitalization with decreased kidney function. Am J Kidney Dis 2012;59:356-63.

22. Harrois A, Libert N, Duranteau J. Acute kidney injury in trauma patients. Curr Opin Crit Care 2017;23:447-56.

23. Shorr AF, Sherner JH, Jackson WL, Kollef MH. Invasive approaches to the diagnosis of ventilator-associated pneumonia: a meta-analysis. Crit Care Med 2005;33:46-53.
24. Fagon JY, Chastre J, Wolff M, et al. Invasive and noninvasive strategies for management of suspected ventilator-associated pneumonia. A randomized trial. Ann Intern Med 2000;132: 621-30.

25. Qiao Z, Yu J, Yu K, Zhang M. The benefit of daily sputum suction via bronchoscopy in patients of chronic obstructive pulmonary disease with ventilators: a randomized controlled trial. Medicine (Baltimore) 2018;97:e11631.

26. Heffner JE, Hess D. Tracheostomy management in the chronically ventilated patient. Clin Chest Med 2001;22:55-69. 